\title{
A seleção brasileira de escritores nos livros didáticos dos anos 70
}

\section{The Brazilian team of writers in the textbooks of the 70 s}

\author{
Suzete de Paula Bornatto
}

\begin{abstract}
RESUMO
O objetivo deste texto é tratar da seleção de autores da literatura brasileira que entrou na escola pelas páginas de livros didáticos de $5^{\mathrm{a}}$ a $8^{\mathrm{a}}$ série do $1^{\circ}$ grau, investigar os critérios dessa seleção durante a década de 70 , no contexto da ditadura, e suas relações com a produção literária. Dialogando com estudo anterior realizado pelo escritor Osman Lins, a análise incide sobre cinco coleções didáticas de português, consideradas como antologias escolares que contribuíram tanto para a preservação do cânone brasileiro quanto para a formação de leitores e a democratização da cultura letrada. Por fim, analisa-se o caso de um escritor frequente nos livros didáticos, Stanislaw Ponte Preta, que, tendo sido autor de textos de crítica à ditadura, esteve representado na escola apenas como autor de textos humorísticos.
\end{abstract}

Palavras-chave: leitura escolar; ditadura; livro didático de português; Stanislaw Ponte Preta.

\begin{abstract}
This paper's aim is to treat the selection of authors in the Brazilian literature that entered the school through the pages of textbooks from the $5^{\text {th }}$ to the $8^{\text {th }}$ grades, investigating the criteria of this selection in the $70 \mathrm{~s}$, in the dictatorship context, and its relations with the literary production. In dialogue with a previous study conducted by the writer Osman Lins, the analysis focuses on five Portuguese teaching collections, considered as school anthologies that have contributed so much to the preservation of the Brazilian canon as well as to the formation of readers and democratization of literacy. Finally,
\end{abstract}

1 Universidade Federal do Paraná (UFPR), Setor de Educação. Rua General Carneiro, $\mathrm{n}^{\circ}$ 460, Curitiba, Paraná, Brasil. CEP: 80060-150. Membro do NUPES - Núcleo de Pesquisas sobre a Educação dos Sentidos e das Sensibilidades e do NEPHEM - Núcleo de Estudos e Pesquisas História, Educação e Modernidade. 
we analyze the case of a frequent writer of textbooks, Stanislaw Ponte Preta, that, having authored critical texts against the Brazilian dictatorship, was represented at the school just as the author of humorous texts.

Keywords: school reading; dictatorship; Portuguese textbooks; Stanislaw Ponte Preta.

\section{Introdução}

A censura prévia de livros, periódicos, espetáculos públicos e programas de rádio e televisão foi regulamentada pelo governo militar brasileiro em 1970; em 1973, foi proibido também mencionar a censura. Conforme registra Sandra Reimão (2011, p. 12), o jornal O Estado de São Paulo, por exemplo, publicou poemas no lugar dos textos censurados. A partir de julho de 1974, o Estadão utilizou trechos de Os Lusíadas, de Camões, mais de seiscentas vezes para substituir matérias não aprovadas, enquanto outros jornais e revistas recorreram a receitas ou ilustrações.

Para os leitores mais avisados, os poemas no jornal eram uma senha para a identificação da censura. Nesse contexto específico, a poesia cumpriu um papel de preenchimento de espaço - sem pretensão de dizer alguma coisa por si - contribuindo, talvez, para certa associação entre o gênero e uma postura de alienação, desinformação, alheamento diante da realidade (se não se pode ler uma notícia séria, leia-se um poema).

No contexto escolar, porém, os textos literários cumpriam finalidades curriculares - com maior frequência, a de servir de matéria-prima para ampliação de vocabulário ou exercício gramatical; simultaneamente, os textos precisavam atender (ou, pelo menos, não subverter) os propósitos de formação moral da escola.

Os livros didáticos de português (LDPs), mesmo que não utilizados integralmente ou da forma prevista por seus autores/editores, reuniam um repertório de textos que, bem ou mal, poderiam ser lidos/conhecidos (nacionalmente, considerados o incentivo do governo federal à indústria de didáticos e o sistema de distribuição das editoras): poemas, contos, crônicas, trechos de narrativas ou de peças de teatro, organizados didaticamente nas unidades das coleções, ofereciam uma amostra do trabalho de alguns escritores (e de raríssimas escritoras). Quais eram e de quem eram esses textos?

A proposta deste artigo é desenvolver uma reflexão sobre essa seleção dos LDPs sob o regime ditatorial, no período posterior à edição da Lei 5.692/71, privilegiando o aspecto da autoria - os resultados se referem especificamente 
aos escritores selecionados pela escola, não ao estudo dos textos, o que compõe outra etapa da pesquisa. A fim de pensar nas relações entre as escolhas dos organizadores dos LDPs, feitas para um público escolar, e a cultura literária brasileira, é preciso olhar não só as prescrições/restrições legais (a diretriz geral para a escola era privilegiar a comunicação e a expressão oral e escrita), mas também as escolhas editoriais e as experiências de censura do período imediatamente anterior, os anos 60.

Reimão (2011, p. 19) recupera a avaliação de Roberto Schwarz de que, entre 1964 e 1969, havia uma relativa hegemonia cultural da esquerda no país, apesar da ditadura da direita - o governo convivia, portanto, com obras que faziam crítica ao regime. A autora cita os lançamentos da revista Pif-Paf, por Millôr Fernandes, em maio de 1964 e de O Ato e o Fato, por Carlos Heitor Cony, em julho do mesmo ano, como exemplos de resistência ao regime. Entre os romances, Quarup, de Antônio Callado, e O Senhor Embaixador, de Érico Veríssimo, seriam outros exemplos. Mas já entre 1964 e 1965, segundo Elio Gaspari (apud REIMÃO, 2011, p. 23), em sua curta gestão no Ministério da Educação, Suplicy de Lacerda teria organizado o expurgo de bibliotecas e a queima de livros de Graciliano Ramos, Jorge Amado, Paulo Freire e Darcy Ribeiro.

Antes da decretação do AI-5, no final de 1968, a censura teve, segundo ela, atuação "confusa e multifacetada", buscando confiscar material subversivo - atentatório à segurança nacional - ou pornográfico, ofensivo à família e aos costumes. A partir de dezembro desse ano, invasões, prisões e atentados a bomba se ampliam, estendendo a repressão a gráficas e livrarias (HALLEWELL, 2012, p. 642).

Na primeira metade da década de 70, a edição de livros cresceu substancialmente em títulos e em número de exemplares - em 1972, o Brasil ultrapassou a marca de um livro por habitante ao ano (a razão foi de 1,3 livros por habitante). Segundo alguns levantamentos citados por Reimão, o número de livros censurados não teria ultrapassado duzentos, mas Deonísio da Silva (1989), em Nos bastidores da censura, arrola 430 livros, dos quais 92 são de autores brasileiros - e dentre esses, dois terços são enquadrados como eróticos ou pornográficos.

$\mathrm{Na}$ área musical, conforme Ana Maria Bahiana (2006, p. 54), os compositores mais censurados do período eram Odair José (47 títulos esbarraram na categoria "moral e bons costumes") e Chico Buarque. Bahiana menciona que a canção "Tortura de amor", de Waldick Soriano, de 1962, regravada em 1974, sofreu censura por chamar a atenção para a tortura, que não podia ser mencionada.

A reação à lei da censura prévia de 1970, que reuniu escritores, a OAB e a Academia Brasileira de Letras, teria levado o governo a isentar de verificação as "publicações e exteriorizações de caráter estritamente filosófico, científico, técnico e didático", bem como as que não versassem sobre temas referentes a 
sexo, moralidade pública e bons costumes (REIMÃO, 2011, p. 30). Os livros didáticos, portanto, não eram submetidos ao mesmo crivo dos demais, mas certamente a autocensura preservava a viabilidade comercial das coleções.

\section{Leitura escolar - eleitos e efeitos das antologias}

André Chervel (1998) cita a história da obra dos grandes dramaturgos gregos da Antiguidade como exemplo emblemático do poder da cultura escolar. Embora se saiba que Ésquilo havia escrito em torno de 24 tragédias ou dramas, não são conhecidas mais do que sete de suas peças - a explicação para esse "desastre", depois confirmada por outras pesquisas, foi apresentada pelo filólogo alemão Wilamowitz: no início da era cristã, subsistiam duas edições da obra do dramaturgo: uma edição completa das tragédias e uma seleta de sete peças que a escola da Antiguidade incluiu no programa por conta de seu interesse pedagógico particular. Foram essas sete tragédias que sobreviveram à Idade Média.

Assim, conforme Chervel, quando lemos Ésquilo hoje, acreditamos ler a obra de um dramaturgo grego: nós lemos na verdade apenas as obras escolhidas para uso dos alunos de uma outra época, um "Ésquilo para a juventude". A imagem que fazemos da cultura antiga é, portanto, uma imagem deformada, pois passou através do filtro do ensino escolar, sendo impossível para nós acessar essa parte da cultura da Antiguidade que não foi carimbada com o rótulo de "boa para as crianças das escolas".

O linguista chama de "efeito Wilamowitz" essa transformação profunda que a escola imprime, de uma forma ou de outra, à cultura. Segundo o autor, poderíamos supor que o azar que atingiu a tragédia grega é um fenômeno histórico ligado ao caráter antigo dessa cultura, e que a invenção sucessiva da imprensa, da eletricidade, do computador ou da internet nos colocaria logo ao abrigo de todas as catástrofes dessa espécie, retirando da escola este poder incontrolável de "falsificar" e de alterar uma cultura sob o pretexto de que a tarefa de formação das crianças não tolera uma transmissão pura e simples das obras e teorias, e exige, ao contrário, escolhas, adaptações, transformações. Entretanto, para Chervel, o papel da escola nesse domínio não parou de crescer e a cultura de nossas sociedades está profundamente impregnada de diversos elementos de origem puramente escolar, ou ligados ao funcionamento do sistema escolar.

No contexto francês, Emmanuel Fraisse (1997) estuda a tradição das antologias literárias e também a importância cultural das antologias escolares. Menciona, por exemplo, uma "querela dos manuais" na década de 20, quando se 
reclamava da ausência de determinados autores (como Verlaine e Baudelaire) e da presença de outros (FRAISSE, 1997, p. 253). Problematizando os critérios dos organizadores dessas obras, o autor fala da dificuldade de inclusão de escritores contemporâneos, ainda não legitimados em âmbito acadêmico.

Para Fraisse, constituir uma antologia é selecionar e ordenar um conjunto de textos de determinados autores - em que o organizador partilha seus gostos, julgamentos e as referências de seu círculo de pertencimento. A antologia fixa ou redefine o cânone, desempenha um papel tão ideológico quanto literário - seu autor assume o papel de herdeiro e de repassador. Nesse sentido, mesmo quando não tem explícita destinação "escolar", a antologia é um gênero pedagógico.

Batista (2009, p. 3) analisa que, no percurso da pesquisa histórica brasileira sobre a leitura escolar, sua transmissão e apropriação, primeiro houve interesse pela descrição e análise dos conteúdos ideológicos, valores morais e cívicos que buscava transmitir, supondo haver "uma coincidência, em princípio necessária, entre os supostos conteúdos dos textos e os significados que se gravariam na mente dos leitores, assim como entre os efeitos visados pelos primeiros e aqueles de fato realizados por sua leitura"; depois, porém, alguns deslocamentos se originaram sobretudo de pesquisas históricas sobre a leitura ou de investigações sobre o consumo cultural.

Os estudos brasileiros teriam se movido, sob o impacto dessa mudança, "do texto para as práticas de leitura que dele se apropriam". Batista, entretanto, insiste que, embora não tenha existência abstrata e "não possa sempre ser analisado independentemente dos suportes que o oferecem à leitura, o texto é o produto material de uma atividade discursiva que visa construir uma determinada compreensão e exercer um conjunto de efeitos ou ações sobre o leitor" (BATISTA, 2009, p. 5).

Do ponto de vista institucional, na escola não se deve ler qualquer coi$\mathrm{sa}$, apenas textos e/ou livros selecionados. Na tradição do ensino, os textos precisam ser exemplares não só do ponto de vista linguístico, mas também moral. Considerando-se, todavia, o grande repertório de textos publicados que atenderiam esses requisitos, é importante observar como a produção didática delimita o universo de leituras a autores consagrados (que não coincidem com os "populares" ou "mais lidos") e, por outro lado, abre espaço para escritores ainda sem reconhecimento de público ou crítica. O estudo histórico dos livros escolares possibilita identificar seleções e apagamentos que vão compondo uma cultura literária escolar - um referencial comum aos cidadãos escolarizados.

De acordo com Jayme Ginzburg (2004, p. 98-99), a discussão sistemática sobre cânone no Brasil, desde a década de 80 , incide sobre o problema dos critérios de valor estético. Ele cita autores como Coutinho e Reis, que discutem o caráter excludente da tradição canônica no Brasil, e enfatiza que a reprodução 
passiva do cânone na formação de estudantes constitui uma limitação na expectativa de desenvolvimento de pensamento crítico.

O cânone em questão é aquele das aulas de literatura, que estão no programa do $2^{\circ}$ grau (hoje Ensino Médio), mas, na década de 70, os LDPs de $5^{\mathrm{a}}$ a $8^{\mathrm{a}}$ série tinham o mérito de trazer autores contemporâneos cuja obra circulava socialmente, não a partir da escola. Nesses livros, cuja intenção não era ensinar literatura (ainda que pudessem tratar de enredo ou métrica, por exemplo), é sobretudo a partir dos anos 80 que se amplia a inserção de textos produzidos para "consumo escolar", isto é, de autores que não são lidos fora do contexto da escola.

$\mathrm{Na}$ década de 70, tratava-se ainda de textos recolhidos de livros autorais, antologias ou da imprensa - não necessariamente elaborados para o leitor em formação, criança ou adolescente. Cabia, portanto, ao autor/organizador do livro didático escolher textos "apropriados" aos estudantes - e se o texto era tomado de uma antologia editada por um(a) especialista, já era meio caminho andado. Um LDP desse nível de ensino não tem o compromisso de apresentar os supostos "melhores textos" de cada autor, apenas bons textos - exemplares, formadores ou apenas (como se isso fosse pouco!) divertidos.

A análise das referências dos textos nas cinco coleções de LDPs aqui utilizadas como amostra conduz, por sua vez, a seleções anteriores - trata-se de onze antologias publicadas a partir do final da década de 50:

\begin{tabular}{|l|c|}
\hline TÍTULO (EDITORA) & DATA DE EDIÇÃO \\
\hline $\begin{array}{l}\text { Antologia poética para a infância e a juventude, org. Henriqueta } \\
\text { Lisboa (Ediouro; Revista dos Tribunais; Instituto Nacional do Livro) }\end{array}$ & 1959 \\
\hline $\begin{array}{l}\text { Poesia brasileira para a infância, org. Cassiano Nunes e Mário da } \\
\text { Silva Brito (Saraiva) }\end{array}$ & 1960 \\
\hline Violão de rua I, II e III, org. Moacyr Félix (CPC da UNE) & 1962 e 1963 \\
\hline Antologia Luso-Brasileira,org, Wagner Ribeiro (FTD) & 1964 \\
\hline $\begin{array}{l}\text { Guia Poético da cidade do Rio de Janeiro, org. Luiz Castro } \\
\text { (Civilização Brasileira) }\end{array}$ & 1965 \\
\hline Antologia Escolar Brasileira, org. Marques Rebelo (MEC/FENAME) & 1967 \\
\hline $\begin{array}{l}\text { Poesia Viva I, org. Affonso Romano de Sant'Anna (Civilização } \\
\text { Brasileira), col. que não teve continuidade }\end{array}$ & 1968 \\
\hline Quadrante (coletânea) (Ed. do Autor). & 1968 \\
\hline Canto melhor, org. Manuel Sarmento Barata (Paz e Terra) & 1969 \\
\hline $\begin{array}{l}\text { Antologia da Nova Poesia Brasileira, sel. Fernando Ferreira de } \\
\text { Loanda (Ed. Orfeu) }\end{array}$ & 1970 \\
\hline Elenco de cronistas modernos (Sabiá) & 1974 \\
\hline
\end{tabular}

QUADRO 1 - ANTOLOGIAS QUE SERVIRAM DE FONTE AOS LDPs FONTE: A autora. 
Como se observa, a década de 60 foi rica nesse tipo de obra, contemplando desde antologias "oficiais", como a do MEC/FENAME ou aquela assumida pelo Instituto Nacional do Livro, até as "revolucionárias", como a Coleção Violão de rua. A Antologia editada pelo MEC foi encomendada a Marques Rebelo, da Academia Brasileira de Letras, e segue o mesmo critério da Antologia Nacional - referência até os anos 60 (RAZZINI, 2000) - de só incluir autores mortos. Várias outras, porém, destacam a contemporaneidade, aludindo a "Poesia viva" ou "nova poesia".

A Violão de rua fazia parte dos Cadernos do Povo Brasileiro, editados pelo Centro Popular de Cultura (CPC) da UNE, entre 1961 e 1963, e tinha o título extra de Poemas para a Liberdade. Entre os oito poetas do volume I estavam Ferreira Gullar (que foi diretor do CPC), Thiago de Mello, Paulo Mendes Campos, Vinícius de Moraes e José Paulo Paes.

No início dos anos 70, a Editora José Olympio lança a Coleção Brasil Moço - literatura viva comentada, organizada por Paulo Rónai, com várias "Seletas", mostrando a necessidade de atualizar o repertório literário e aproximar as novas gerações dos escritores em atividade. Tais coleções estabeleciam um contraponto à Coleção Nossos Clássicos, da Editora Agir, iniciada em 1957, sob a coordenação de Alceu Amoroso Lima (no Brasil) e Jorge de Sena (em Portugal), que também só trazia autores mortos.

\section{O cânone das coleções didáticas}

Será inoportuno, e mesmo ilícito, em país como o nosso, com tantos problemas graves a enfrentar, deter-se um homem a analisar a política que rege a escolha de textos literários através dos quais, nos estabelecimentos onde se ministra, para uma exígua fração de nossa juventude, o curso secundário, vão os alunos formar uma ideia - ideia que, devendo ser provisória, não raro se perpetua - do que seja escrever, do que seja um escritor? (LINS, 1977, p. 31)

Nos anos 70, a eficiência do ensino deveria se mostrar na preparação de cidadãos que soubessem se comunicar bem - oralmente e por escrito. Não havia um programa nacional detalhando temas a serem abordados, como nos anos 40, quando pátria, família, virtudes, fatos históricos e grandes vultos eram itens obrigatórios. O critério da correção moral e linguística, porém, é preservado 
porque considerado inerente ao contexto escolar. Quanto ao critério literário, nem sempre prepondera, uma vez que a extensão do texto, o tempo exigido para sua leitura, assim como a adequação a um tema ou tópico de ensino, se revelam mais importantes (não é à toa que "Um apólogo" é o texto mais frequente de Machado de Assis no século XX - é seu conto mais curto).

Para Zilberman (1996, p. 26), os livros de "Comunicação e Expressão" (denominação dada à disciplina de Português no $1^{\circ}$. grau pela Lei 5.692/71) da década de 70 não mudaram, em relação às obras anteriores, duas noções: de que a leitura literária forma a base do ensino; e de que os textos lidos são passagem para um outro estágio, superior, situado fora do livro didático. As crônicas, nessa perspectiva, seriam apenas um começo, um aperitivo para que os estudantes lessem textos "verdadeiramente valiosos" em sua vida fora da escola ${ }^{2}$.

Preocupado com a formação dos estudantes em relação ao patrimônio cultural brasileiro e reconhecendo a influência dos livros escolares nesse processo, Osman Lins (1977) avaliou a escolha de textos dos LDPs (que ele chama também de livros de gramática) em dois momentos distintos: 1965 e 1975 . Sua principal crítica em 1965 era quanto à falta de autores contemporâneos; em 1975 (LINS, 1977, p. 145) ele registra que, nesse aspecto, os livros melhoraram, mas ainda se ressente de falta de equidade e de algumas ausências, em especial de Graciliano Ramos, Machado de Assis e João Cabral de Melo Neto.

Em relação a Graciliano (LINS, 1977, p. 32, nota 1), Lins menciona um episódio pessoal: após a publicação dos primeiros artigos sobre o tema, ele recebeu a visita de um autor de LDP, a quem perguntou sobre o motivo da ausência de Graciliano em seus compêndios - o autor explicou que "realmente evitara representar o escritor alagoano", já que os livros eram adotados em colégios de freiras e que, se incluísse Graciliano, que fora comunista, era quase certo que as religiosas trocariam de coleção.

As cinco coleções de LDPs escolhidas para compor a amostra ${ }^{3}$ desta pesquisa estavam disponíveis em 2013 na Biblioteca Pública do Paraná, em Curitiba, assim como em acervos de livros usados de diferentes estados do Brasil:

2 Para Zilberman, a utopia da leitura - que a desfigura - seria prometer "uma felicidade que está além dela, mas pela qual não pode se responsabilizar" (ZILBERMAN, 1996, p. 28).

3 Coleções também estudadas por Bulotas (2013), em estudo sobre a poesia nos livros da década de 70 . 


\begin{tabular}{|c|c|c|c|}
\hline Título & Autor(es) & Editora & Séries /data \\
\hline Nossa língua & $\begin{array}{l}\text { Geraldo Mattos e Eurico } \\
\text { Back }\end{array}$ & FTD & $\begin{array}{l}5^{\mathrm{a}} . \text { e } 6^{\mathrm{a}} \cdot-1972 \\
7^{\mathrm{a}} \text {. e } 8^{\mathrm{a}} .-1973\end{array}$ \\
\hline $\begin{array}{l}\text { Meu livro de português - } \\
\text { a língua pelos textos }\end{array}$ & Adriano da Gama Kury & $\begin{array}{l}\text { LISA - Livros } \\
\text { Irradiantes } \\
\end{array}$ & $5^{\mathrm{a}}$. e $6^{\mathrm{a}}$. -1973 \\
\hline $\begin{array}{l}\text { Estudo Dirigido de } \\
\text { Português }\end{array}$ & Reinaldo Mathias Ferreira & Ática & $5^{\mathrm{a}}$ a $8^{\mathrm{a}} .-1974$ \\
\hline $\begin{array}{l}\text { Comunicação, expressão } \\
\text { e criatividade }\end{array}$ & $\begin{array}{l}\text { Audemaro Taranto Goulart } \\
\text { Márcia Teixeira de Sousa } \\
\text { Oscar Vieira da Silva }\end{array}$ & Ed. do Brasil & $5^{\mathrm{a}}$. a $8^{\mathrm{a}} .-1975$ \\
\hline $\begin{array}{l}\text { Comunicação- } \\
\text { atividades de linguagem }\end{array}$ & Reinaldo Mathias Ferreira & Ática & $\begin{array}{l}5^{\mathrm{a}} \text { e } 6^{\mathrm{a}} \cdot-1978 \\
7^{\mathrm{a}} \text {. e } 8^{\mathrm{a}} \cdot-1979\end{array}$ \\
\hline
\end{tabular}

QUADRO 2 - COLEÇÕES DE LDPs DE $5^{\mathrm{a}}$. A $8^{\mathrm{a}}$. SÉRIES DA DÉCADA DE 70 FONTE: A autora.

A escolha de duas coleções de Mathias Ferreira reconhece a importância desse autor na história editorial brasileira ${ }^{4}$, por ter sido o sucesso comercial responsável por projetar a Editora Ática no mercado de livros didáticos a partir dessa década, além de permitir comparar obras do início e do final do período. Estudo Dirigido (mais antiga) tem mais textos, explicações e exercícios, enquanto Comunicação é uma produção simplificada em termos de conteúdo.

No total, o autor contemporâneo (à época, vivo ou falecido há menos de trinta anos) que mais aparece nessas coleções (27 vezes) é Carlos Drummond de Andrade. Embora se possa criticar, como fez Osman Lins, que o poeta apareça nos LDPs mais como cronista ${ }^{5}$, sua presença faz jus à importância que lhe é atribuída por críticos e historiadores da nossa literatura. Em seguida vem Fernando Sabino, com 23 textos, e Manuel Bandeira, com 21. Sabino prossegue hoje como referência "escolar" por conta das edições paradidáticas de seus textos, mas não é um autor que a crítica costume revisitar ou defender do esquecimento. Bandeira, por sua vez, é uma unanimidade nacional com presença certa nos LDPs desde os anos $50^{6}$.

4 Ver Hallewell (2012, p. 616).

5 Cf. Reimão (2011), um livro de crônicas de Drummond estava na lista dos mais vendidos da revista. Veja no ano de 1975.

6 Cf. Bornatto (2011). 


\begin{tabular}{|l|c|}
\hline AUTOR(A) & Número de textos \\
\hline Carlos Drummond de Andrade & 27 \\
\hline Fernando Sabino & 21 \\
\hline Manuel Bandeira & 12 \\
\hline Cassiano Ricardo & 12 \\
\hline Cecília Meireles & 11 \\
\hline Rubem Braga & 10 \\
\hline Jorge de Lima & 10 \\
\hline Guilherme de Almeida & 7 \\
\hline Vinícius de Moraes & 6 \\
\hline Paulo Mendes Campos & 5 \\
\hline Stanislaw Ponte Preta & 5 \\
\hline Guimarães Rosa & 23 \\
\hline
\end{tabular}

QUADRO 3 - AUTORES MAIS FREQUENTES NOS LDPs ANALISADOS FONTE: A autora.

Dos doze autores mais frequentes, oito são (ou são também) poetas, o que é bastante significativo num país em que os poetas reclamam não serem lidos. Na comparação com o levantamento feito por Lins em 1975, em outras coleções ${ }^{7}$, percebe-se que os três mais citados coincidem: lá Drummond e Sabino aparecem 20 vezes; Bandeira, 18; Ponte Preta é citado 10 vezes; Rubem Braga e - novamente a única mulher - Cecília Meireles, 8. Lins conclui: "Se o escritor nacional, no momento, aspira ingressar nesses compêndios, tem duas vias a seguir: ou escrever crônicas em jornal ou escrever para a infância" (LINS, 1977, p. 147).

Em Estudo Dirigido de Português, de Mathias Ferreira, além dos autores listados, constam Dalton Trevisan, Clarice Lispector e Thiago de Mello; em Comunicação, o repertório é diferente, mas lá estão Millôr Fernandes, Graciliano Ramos, Rubem Braga e Lygia Fagundes Telles. A coleção Comunicação, expressão e criatividade, reunindo todos os termos-chave para o ensino "mo-

7 Autores dos LDPs analisados por Lins: Dino Preti, J. França Miranda, Jairo F. Martins, Roberto Mesquita e Cloder Martos, Floriano Tescarolo e Lafayete Megale, Francisco Maranhão. 
derno" da época, preza pelos autores contemporâneos, incluindo José J. Veiga, Autran Dourado, Mário Palmério e Adonias Filho. Já os livros de Adriano Kury trazem pelo menos um terço de autores do século XIX e início do XX, o que já não era habitual, principalmente nos volumes de $5^{\mathrm{a}}$ e $6^{\mathrm{a}}$ série.

Curiosamente, no mesmo volume de $5^{\text {a }}$ série da coleção de Kury (1973) em que há três textos de Graciliano Ramos, está também o texto "Visão do Nordeste (Mensagem de esperança)", de um autor "inesperado", o General Médici. Kury alega que "o Pres. Emílio Garrastazu Médici é um dos poucos presidentes que temos tido que alia às qualidades de governante a sensibilidade literária". Vai além na louvação: “O seu discurso 'Visão do nordeste' pode aproximar-se às páginas admiráveis de um Graciliano Ramos...” (KURY, 1973, p. 83). Poupo os leitores da continuação, dizendo que o discurso do então presidente serviu para o ensino da "ênfase".

O que interessa notar aqui é que o histórico comunista de Graciliano Ramos perdeu força diante de sua legitimação literária, e sua presença no LDP não representa ameaça. A rejeição ao comunismo que afeta Graciliano não atinge, porém, Rachel de Queiroz, escritora que em 1964 fazia parte do IPES (Instituto de Pesquisas e Estudos Sociais), organização financiada por empresas privadas e anticomunistas, segundo Hallewell (2012, p. 607) e, em 1966, compunha o Conselho Federal de Cultura, ao lado de Peregrino Júnior e Cassiano Ricardo, tendo por secretário Manuel Bandeira - os dois últimos, coincidentemente ou não, estão no topo da lista dos mais frequentes nos LDPs.

É interessante observar também - o que enseja outro caminho de pesquisa - o papel dos escritores como editores e antologistas, o que certamente amplia as possibilidades de circulação e utilização de seus textos. A Editora do Autor, por exemplo, espécie de cooperativa de autores, teve como um de seus fundadores Manuel Bandeira; em 1966, seus ex-diretores Rubem Braga e Fernando Sabino criam a Sabiá, cuja edição de Para uma menina com uma flor, de Vinícius de Moraes, vendeu 50 mil exemplares em quatro anos. Além de Vinícius e dos próprios Braga e Sabino, a Sabiá publicou Paulo Mendes Campos, João Cabral de Melo Neto, Clarice Lispector, Murilo Mendes, Drummond e Chico Buarque.

\section{O caso Stanislaw}

Stanislaw Ponte Preta - trocadilho com "Serafim Ponte Grande", de Oswald de Andrade - era pseudônimo do jornalista Sérgio Porto, que utilizava sua agência de notícias "Pretapress" para reunir informações enviadas por 
leitores de todo o Brasil. Ponte Preta é autor de sete livros pelas Editoras "do Autor" e "Sabiá", alguns apenas de crônicas, outros reunindo notas e crônicas publicadas no jornal Última Hora.

Em 1966, dois anos após o que ele chama de "a redentora", Ponte Preta publica o Febeapá I - Festival de besteira que assola o país (segundo o prefácio do volume II, o primeiro teria vendido 37 mil exemplares, sucesso que surpreendeu o mundo editorial). Para esse festival contribuíam todos os autores de atos questionáveis, abusivos ou absurdos. São desse volume notas como as seguintes: "O Ministro da (que Deus nos perdoe) Educação, sr. Suplicy de Lacerda, que viria a se tornar um dos mais eminentes membros do Festival, disse que ia diminuir os cursos superiores de cinco para quatro anos" (PONTE PRETA, 1969a, p. 6); “estreou no Teatro Municipal de São Paulo a peça clássica 'Electra', tendo comparecido ao local alguns agentes do DOPS para prender Sófocles, autor da peça e acusado de subversão" (PONTE PRETA, 1969a, p. 12).

Apesar da irreverência e do humor, nem tudo se mostra divertido, nem todas as crônicas fazem rir. Em "Patrimônio", um homem pobre, Benedito Lopes, vai ao cartório registrar o quinto filho e pensa dar-lhe o nome de "General" (portanto, "General Lopes"), imaginando promover assim um futuro melhor para a criança: "Quem sabe, quando ele crescer, os outros chamando ele de General, talvez, não sei... Talvez ele consiga ser mais do que eu fui... o senhor compreende?" (PONTE PRETA, 1969a, p. 158). Mas o cartorário não compreende, não aceita, e ele se resigna a que o filho se chame João.

A presença do autor em um LDP também é tema de crônica: "O Antológico Lalau". O narrador conta que recebeu um exemplar da Antologia para o Ensino Médio de Português, com dedicatória de M. Cavalcanti Proença ${ }^{8}$, em que estavam incluídas duas crônicas suas. Lendo as questões que os alunos deveriam responder sobre os textos, Stanislaw começa a ficar aflito - nem ele mesmo saberia respondê-las todas: "Coitados dos menininhos que estiverem estudando meu texto. Eu, que escrevi, estou aqui meio sobre o embasbacado com essa tal de translação do sentido, imaginem as crianças do ensino médio!" (PONTE PRETA, 1969a, p. 57):

De repente, a minha aflição aumenta assustadoramente. Lembro-me que, no tempo de estudante, eu e toda a minha turma odiávamos Camões por causa das análises dos "Lusíadas" a que nos obrigava o professor de Português. Puxa vida... com a minha promoção a antológico, breve vai

8 A antologia em questão tinha o ambíguo título de Rio de todo mundo e foi publicada pela EDILD, no Rio de Janeiro, em 1965. 
ter garoto aí me achando o maior chato do ano letivo. [...] Preciso abrir os olhos. Camões não o fez porque só tinha um olho, mas eu estou com os dois em dia. É necessário abri-los. (PONTE PRETA, 1969a, p. 57)

Em Febeapá II (1 $1^{\mathrm{a}}$. ed 1967, $7^{\mathrm{a}}$. ed em 1969), há alusões a diversos episódios de espancamento de estudantes pela polícia: "Abril em Porto Alegre - Os estudantes continuavam apanhando com grande regularidade, principalmente no Rio, São Paulo, Belo Horizonte, Brasília, Recife, Salvador e - a partir de abril - em Porto Alegre." (PONTE PRETA, 1967, p. 34); "Festival revigorado. [...] Logo de saída, o Governo nomeava o ex-Ministro da Educação, Flávio Suplicy de Lacerda, que foi um suplício para os estudantes, para Reitor da Universidade do Paraná" (PONTE PRETA, 1967, p. 43). Adiante, fala da violência da Polícia mineira contra professoras primárias, que protestavam contra o atraso nos salários (PONTE PRETA, 1967, p. 56) e noticia o recolhimento de livros considerados subversivos - em vez de incinerados pelos militares, seriam recolhidos ao Instituto Nacional do Livro (devido a um acordo da Auditoria Militar com o INL) (PONTE PRETA, 1967, p. 74).

No terceiro volume, Na terra do crioulo doido - Febeapá 3 - A máquina de fazer doido, as referências se repetem, mas chama atenção a crônica "A solução" (PONTE PRETA, 1969b, p. 91-94): o personagem João José é um rapaz "honesto, de bom caráter, que sempre ajudou a família". Desde cedo, órfão de pai, trabalhou para ajudar a mãe e duas irmãs menores. Fez o ginasial à noite, logo percebeu que "era preciso estudar para ser alguma coisa na vida. Mas nunca teve ilusões: era preciso trabalhar e estudar ao mesmo tempo". João José paga, então, "as anuidades, os livros, tudo que precisava" do curso de Farmácia com o soldo da Polícia Militar. Era bom aluno e bom soldado. "No dia em que foi mais sangrenta a luta entre estudantes e polícia, estava de folga no quartel. Nem soube de nada. Aproveitara o dia para repassar a matéria de Química. A faculdade estava fechada, todos em greve, uma lástima." Ao ler o jornal no dia seguinte, porém, entra em crise: "reconheceu policiais, reconheceu vários colegas de faculdade. Começou a ler de novo, correndo a lista de presos, a lista de feridos". Um de seus colegas policiais foi atingido pela população que saiu em defesa dos estudantes. "Já não sabia mais de si mesmo [...] Como estudante, sabia que o protesto era justo. [...] Como policial, seu dever era cumprir ordens [...] Ele teria batido? Ele teria apanhado?” João José veste as calças de estudante e o dolman da PM e começa a bater violentamente em si mesmo, até jorrar sangue de seu rosto e de sua cabeça.

Nos LDPs, Stanislaw Ponte Preta tem incluídas crônicas como "A Velhinha contrabandista", "A vontade do falecido" e outras narrativas humorísticas. O 
leitor estudante poderia guardar algum apreço por seu estilo, se apropriar das histórias - não chegaria a vislumbrar, todavia, sua faceta de crítico da ordem social e do regime. Em termos de impacto da cultura escolar na cultura geral, é fácil perceber que, se de Ésquilo só ficamos com algumas tragédias, de Ponte Preta várias gerações de estudantes só ficaram com as crônicas divertidas.

$\mathrm{Na}$ lista de livros proibidos citada por Silva (1989) aparece o livro $O$ poder jovem - História da participação política dos estudantes brasileiros, de Arthur José Poerner, publicado pela Civilização Brasileira em 1968 (reeditado clandestinamente em 1977); em 1972, Drummond de Andrade publica O poder ultra-jovem, pela José Olympio. Não é possível saber (sem outra pesquisa) se há nesse título uma referência intencional ao livro proibido de Poerner - no livro de Drummond, a crônica que dá origem ao título é uma historinha "ingênua" ("No restaurante"), de um pai que se vê às voltas com a determinação da filha em comer lasanha (e à qual ele acaba cedendo no final, sob o aplauso dos circunstantes). $\mathrm{O}$ texto termina com a seguinte observação do narrador: "Se, na conjuntura, o poder jovem cambaleia, vem aí, com força total, o poder ultrajovem".

Sérgio Porto/Stanislaw Ponte Preta morreu em 1968, antes do AI-5, e é difícil supor o que ele publicaria em 1972, com sua irreverência sob repressão mais intensa do que antes, mas a história de João José, o estudante-policial de "Solução", diante da sutileza desta alusão de Drummond à juventude, se mostrou bem corajosa.

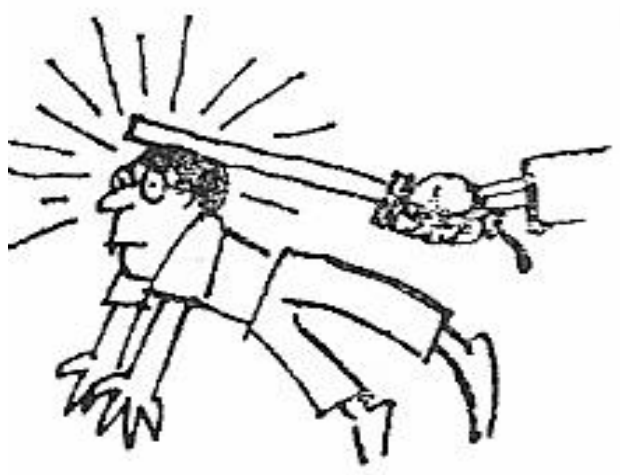

FIGURA 1 - ILUSTRAÇÃO DE JAGUAR À MARGEM DA PÁGINA DO FEBEAPÁ 2 (PONTE PRETA, 1969a, p. 35) 


\section{Conclusões}

Para um estudante, é importante ter lido determinado texto ou determinado autor? Ler Machado ou ler Dom Casmurro? Drummond ou Lição de coisas? A metonímia não é indiferente - ter lido determinado autor parece culturalmente mais valioso do que ter lido este ou aquele livro. No caso dos livros didáticos, um time de bons autores contemporâneos pôde ser lido pelos estudantes na década de 70. Motivações políticas interferiram na seleção? Provavelmente, não mais nem menos do que em outras décadas. Mais produtivo parece o investimento na pesquisa dos círculos sociais e editoriais que garantiram maior visibilidade a alguns escritores que, graças a isso, entraram nos LDPs.

A expectativa em relação a livros editados sob a ditadura era de que seus textos seriam conformes à ideologia do regime, favoráveis à pátria, ao desenvolvimento, e que os autores selecionados eram pessoas "insuspeitas", do ponto de vista das amplas possibilidades de censura na época, mas, em uma avaliação mais minuciosa, essa homogeneização não se verifica. $\mathrm{O}$ nacionalismo aparece menos do que o esperado, há espaço para autores de diferentes opções políticas, desde que literariamente legitimados.

As crônicas, gênero frequente, abordavam temas do cotidiano com leveza, lirismo ou humor - mas, se o estudante seguisse lendo os cronistas nos jornais e livros, teria acesso a textos sobre outros temas, política e socialmente relevantes. O caso de Stanislaw Ponte Preta, cronista escolhido em meio a diversos poetas consagrados presentes nos livros do período, é tão emblemático do estilo de texto com que se desejava conquistar os alunos para a leitura - agradável de ler, divertido - quanto do poder da cultura escolar de reduzir um escritor que se dedicava a questionar a realidade do país a um contador de anedotas.

\section{REFERÊNCIAS}

BACK, E; MATTOS, G. Nossa língua - 5ª série. São Paulo: FTD, 1972. . Nossa língua - 6 a série. São Paulo: FTD, 1972. . Nossa língua $-7^{\mathrm{a}}$ série. São Paulo: FTD, 1973. . Nossa língua - 8 ${ }^{\mathrm{a}}$ série. São Paulo: FTD, 1973.

BAHIANA, A. M. Almanaque dos anos 70. Rio de Janeiro: Ediouro, 2006. 
BATISTA, A. A. G. Leitura escolar e aculturação: a "comunidade dos infelizes". Lectura $y$ vida - International Reading Association, Buenos Aires, v. 30, p. 14-31, 2009.

BORNATTO, S. P. Bandeiras e modernismos nos livros de português. In: CASTRO, G.; PICANÇO, D. C. L. (Org.). Educação, mídia e sociedade: alguns ensaios discursivos. Londrina: EDUEL, 2011.

BULOTAS, M. C. Poesia que se lê na escola - período da ditadura - 1970. In: EVENTO DE INICIAÇÃO CIENTÍFICA, 21., 2013, Curitiba. Relatório de Iniciação Científica. Curitiba: UFPR, out. 2013.

CHERVEL, A. La culture scolaire - une approche historique. Paris: Belin, 1998.

FERREIRA, R. M. Estudo dirigido de português. São Paulo: Ática, 1974.

. Comunicação - atividades de linguagem. 5a série. São Paulo: Ática, 1978. . Comunicação - atividades de linguagem. $6^{\text {a }}$ série. 3. ed. São Paulo: Ática, 1978. . Comunicação - atividades de linguagem. $7^{\mathrm{a}}$ série. 4. ed. São Paulo: Ática, 1979. . Comunicação - atividades de linguagem. $8^{\text {a }}$ série. 3. ed. São Paulo: Ática, 1979.

FRAISSE, E. Les anthologies en France. Paris: Presses Universitaires de France, 1997. GINZBURG, J. Cânone e valor estético em uma teoria autoritária da literatura. Revista de Letras, São Paulo, v. 44, n. 1, p. 97-11, 2004.

GOULART, A. T.; SOUSA, M. T.; SILVA, O. V. Comunicação, expressão e criatividade. $5^{\mathrm{a}}$ série. São Paulo: Editora do Brasil, 1975. 1975. . Comunicação, expressão e criatividade. $6^{\mathrm{a}}$ série. São Paulo: Editora do Brasil, 1975.

Comunicação, expressão e criatividade. $7^{\text {a }}$ série. São Paulo: Editora do Brasil, 1975.

Comunicação, expressão e criatividade. $8^{\text {a }}$ série. São Paulo: Editora do Brasil, HALLEWELL, L. O livro no Brasil - sua história. 3. ed. São Paulo: EDUSP, 2012.

LINS, O. Do ideal e da glória. Problemas inculturais brasileiros. São Paulo: Summus, 1977.

KURY, A. G. Meu livro de português - A língua pelos textos. $5^{\circ}$. 3. ed. São Paulo: Lisa - Livros Irradiantes, 1973.

. Meu livro de português - A língua pelos textos. $6^{\circ}$. 2. ed. São Paulo: Lisa - Livros Irradiantes, 1973.

PONTE PRETA, S. Febeapá I - Festival de Besteira que assola o país. Rio de Janeiro: Sabiá, 1967. 
Febeapá 2 - Segundo Festival de Besteira que assola o país. 7. ed. Rio de Janeiro: Sabiá, 1969a [1967].

Na terra do crioulo doido - Febeapá 3 - A máquina de fazer doido. 3. ed. Rio de Janeiro: Sabiá, 1969b.

RAZZINI, M. P. G. O espelho da nação: a Antologia Nacional e o ensino de português e de literatura (1838-1971). Tese (Doutorado em Letras) - Instituto de Estudos da Linguagem, Universidade Estadual de Campinas, Campinas, 2000.

REIMÃO, S. Repressão e resistência - censura a livros na ditadura militar. São Paulo: EDUSP; FAPESP, 2011.

SILVA, D. Nos bastidores da censura: sexualidade, literatura e repressão pós-64. São Paulo: Estação Liberdade, 1989.

ZILBERMAN, R. No começo, a leitura. Em Aberto, Brasília, DF, ano 16, n. 69, p. 15 29, jan./mar. 1996.

Texto recebido em 05 de janeiro de 2014. Texto aprovado em 14 de fevereiro de 2014. 